\title{
Clinical study on presentation and management of ectopic pregnancies in a tertiary care centre
}

\author{
Anjum Ara*, Indu Chawla, Rasika Agarwal, Bangali Manjhi
}

Department of Obstetrics and Gynecology, ABVIMS and Dr. RML Hospital, New Delhi, India

Received: 10 November 2019

Accepted: 09 December 2019

\section{*Correspondence:}

Dr. Anjum Ara,

E-mail: life_dranjum@yahoo.com

Copyright: (C) the author(s), publisher and licensee Medip Academy. This is an open-access article distributed under the terms of the Creative Commons Attribution Non-Commercial License, which permits unrestricted non-commercial use, distribution, and reproduction in any medium, provided the original work is properly cited.

\begin{abstract}
Background: Ectopic pregnancy means pregnancy outside the normal uterine cavity. It is the leading cause of maternal morbidity and mortality in first trimester. Early diagnosis and timely intervention can significantly improve the outcomes.

Methods: Retrospective observational study done in the department of obstetrics and gynecology ABVIMS and Dr. RML hospital, New Delhi from January 2016 to March 2019. Case records of 76 patients of confirmed ectopic pregnancy were retrieved and studied from the medical record section. The main aims were to see the clinical presentation, mode of diagnosis, predisposing risk factors; treatments offered and associated morbidity and mortality.

Results: The incidence of ectopic pregnancy in present study was $1.7 \%$, highest in 21 to 30 years age multiparous patients. $85.1 \%$ presented as acute emergencies, $75 \%$ patients had classic triad of amenorrhea, pain and bleeding. Pain was the commonest symptom in $96.1 \%$. The commonest clinical sign was adnexal mass and tenderness. Ultrasound findings had adnexal mass in $98.7 \%$ and free fluid in $84.7 \%$ cases with empty uterus in $100 \% .90 .7 \%$ case were tubal ectopic and $69.73 \%$ were ruptured. Surgery was the main treatment modality in $96.0 \%$ cases. Salpingectomy was the commonest surgery in $80.25 \%$. There was $0 \%$ mortality and $78.9 \%$ cases required blood transfusions, $44.7 \%$ patients had no known risk factors whereas some of the common identifiable risk factors were history of previous abortion, previous pelvic surgeries and pelvic inflammatory disease.

Conclusions: ABVIMS and Dr. RML hospital is a tertiary care center so majority of patients with ectopic pregnancies presented late, as such surgery was the main treatment modality but there was $0 \%$ mortality in our study. Conservative treatments such as laparoscopy and medical management can also be offered to hemodynamically stable patients.
\end{abstract}

Keywords: Ectopic pregnancy, Mortality, Risk factors, Morbidity

\section{INTRODUCTION}

Implantation of a fertilized ovum in a place other than endometrium of uterus results in an ectopic pregnancy. The Greek word extopos means out of place, from which the name came. Ectopic pregnancy can occur in tube, ovary, abdomen, cervix, LSCS scar, cornua of uterus, bicornuate horn, abdomen but commonest site is fallopian tube which accounts for nearly $90 \%$ cases. ${ }^{1}$ The overall incidence ranges from 1 to 2 percent but still it is one of the leading causes of maternal morbidity and mortality in first trimester. ${ }^{1-3}$ Though the incidence of ectopic is increasing due to rise in PID and its treatment, use of intrauterine devices and artificial reproductive techniques but there has been a dramatic decrease in mortality and morbidity associated with ectopic due to timely detection and early interventions., ${ }^{4,5}$

In recent years there has been tremendous advance in diagnosis of ectopic pregnancy with use of high- 
resolution ultrasound TAS/TVS. Presence of an adnexal mass with or without gestation sac and cardiac activity with an empty endometrial cavity strongly suggests diagnosis of ectopic pregnancy. Sometimes an abnormal gestation sac is seen at the lower part of uterus at the scar site or in the cervix with empty endometrial cavity in cervical or scar site pregnancies also. On color doppler study the presence of ring of fire sign and increased vascularity around ectopic gestational sac is quite significant. Presence of free fluid in abdomen and its quantification can predict rupture of ectopic pregnancy.,

Blood level of $\beta$ HCG are quite helpful in both diagnosis and planning of management. Serum value of $1500 \beta$ HCG and no intrauterine G sac strongly suggests ectopic pregnancy. Doubling $\beta \mathrm{HCG}$ in 48 hours is seen in normal intrauterine pregnancy (IUP) and failure of doubling goes in favor of ectopic pregnancy. ${ }^{7} \beta$ HCG less than 5000 the success of medical management is high. With value less than 1000 the success of expectant management is high. ${ }^{6}$

Patients with ectopic pregnancy presents with clinical trial of amenorrhea, bleeding and pain. Some may present as acute abdomen with or without shock. In a female patient of reproductive age group presenting with acute abdomen ectopic pregnancy must always be ruled out.

Ectopic pregnancy can result in spontaneous resolution, tubal abortion and rupture leading to haemoperitoneum, hematosalpinx, rupture followed by secondary abdominal pregnancy and sometimes may persist as chronic adnexal mass. Rupture can be devastating and leads to hemodynamic instability of patient and urgent laparotomy is required in such cases.

Medical management can also be offered if patients are haemodynamically stable, size of the adnexal mass is less than $3.5 \mathrm{~cm}$, there is absence of cardiac activity and beta HCG is less than 5000. These include systemic or local injection of methotrexate and local injection of KCL. Measures like uterine artery embolization can be used to reduce bleeding in cervical pregnancies and scar site pregnancies. Expectant management can also be used in stable patients where levels of beta HCG are less than 1500 , decreasing and patient is willing for follow-up.

\section{METHODS}

A retrospective observational study was performed in the department of obstetrics and gynecology in ABVIMS and Dr. RML hospital New Delhi from January 2016 to March 2019. Patients admitted in Dr. RML hospital with diagnosis of ectopic pregnancy during the study period.

\section{Inclusion criteria}

- Patients with confirmed clinical diagnosis of ectopic pregnancy.
Data collection was done from the case records of these patients, case sheets were traced through their ward admissions numbers and OT records. Total 76 patients of confirmed ectopic pregnancy were studied. The main aims were to see the clinical presentation of these patients, modalities used in diagnosis, treatment offered and analyze incidence of ectopic pregnancy, their predisposing risk factors and associated morbidity and mortality.

Information was recorded in a present proforma, data was entered in MS excel spreadsheet and analyzed. Continuous variables data were calculated as Mean \pm SD and categorical variable data was compiled as frequency and percentage.

\section{RESULTS}

During the study period total 15,010 patients were admitted in department of obstetrics and gynecology and 4,223 deliveries occurred. Out of these 76 patients were diagnosed as ectopic pregnancies. The incidence of ectopic pregnancy was $1.7 \%$. In this study highest incidence was seen in 21 to 30 years age group and majority of patients $71 \%$ were multigravida (Table 1). $85.1 \%$ presented as acute abdomen whereas $14.4 \%$ presented as chronic cases.

Table 1: Baseline characteristics.

\begin{tabular}{|lcl|}
\hline Baseline characteristics & No. of patients & $\%$ \\
\hline Age group & \multicolumn{2}{l|}{} \\
\hline$<20$ years & 2 & $2.60 \%$ \\
\hline $21-25$ & 20 & $26.30 \%$ \\
\hline $26-30$ & 26 & $34.20 \%$ \\
\hline $31-35$ & 22 & $28.90 \%$ \\
\hline$>35$ & 6 & $7.80 \%$ \\
\hline Parity & & \\
\hline Primi & 22 & $28.90 \%$ \\
\hline Multi & 54 & $71.10 \%$ \\
\hline Presentation as acute or chronic & \\
\hline Acute & 65 & $85.10 \%$ \\
\hline Chronic & 11 & $14.40 \%$ \\
\hline Symptoms & & $82.90 \%$ \\
\hline Amenorrhea & 63 & $88.20 \%$ \\
\hline Bleeding & 67 & $96.10 \%$ \\
\hline Pain & 73 & $17.10 \%$ \\
\hline Syncope & 13 & $75.00 \%$ \\
\hline Classic triad & 57 & $51.30 \%$ \\
\hline Hemodynamics & & $23.70 \%$ \\
\hline Stable & 39 & $25 \%$ \\
\hline Tachycardia & 18 & \\
\hline Shock & 19 & \\
\hline
\end{tabular}

A total $75.0 \%$ patients presented with classic triad of amenorrhea, pain and bleeding. The commonest symptom was pain present in nearly $96.1 \%$ of patients. The mean gestational age at the time of diagnosis was $7.5 \pm 1$ weeks. 


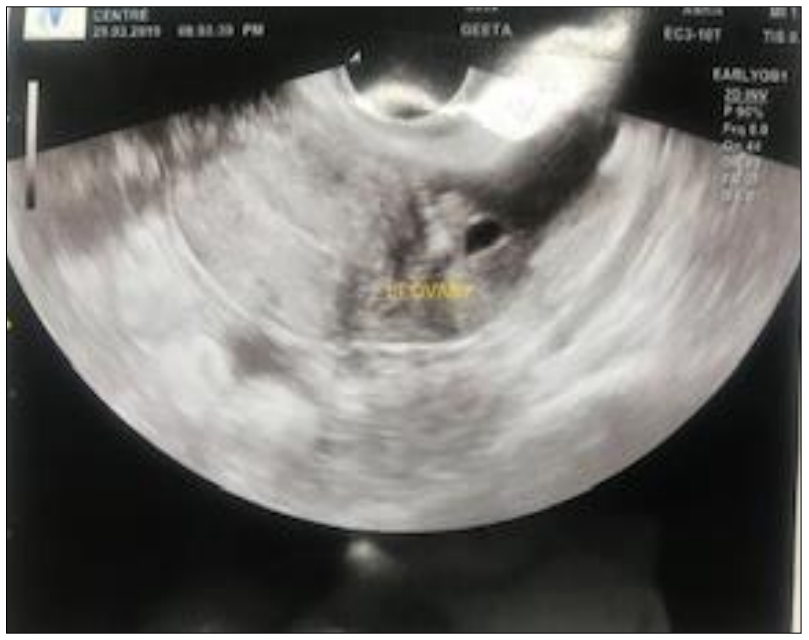

Figure 1: Transvaginal ultrasound of ectopic sac in left adnexa.

Table 1: Ultrasound findings.

\begin{tabular}{|lll|}
\hline USG findings & No of patients & $\%$ \\
\hline Adnexal mass & 75 & $98.7 \%$ \\
\hline G. Sac in adnexal mass & 17 & $22.4 \%$ \\
\hline Cardiac activity & 4 & $5.3 \%$ \\
\hline Free fluid in abdomen & 64 & $84.2 \%$ \\
\hline
\end{tabular}

Pallor was present in $62 \%$ cases. $25 \%$ patients presented with shock whereas $23.7 \%$ had only tachycardia and rest were with stable vitals. The commonest clinical sign was adnexal mass and tenderness. Urine pregnancy test was positive in $100 \%$ of patients. The diagnosis was confirmed on ultrasound with adnexal mass present in $98.7 \%$ of cases and empty uterine cavity in $100 \%$ of patients (Figure 1). Free fluid was present in $84.7 \%$ cases (Table 2).

Table 3: Incidence as per site of ectopic pregnancy.

\begin{tabular}{|lll|}
\hline Site of pregnancy & No of patients & $\%$ \\
\hline Ampullary & 37 & $48.68 \%$ \\
\hline Isthmic & 19 & $25 \%$ \\
\hline Fimbrial & 0 & $0 \%$ \\
\hline Ovarian & 0 & $0 \%$ \\
\hline Bicornuate horn & 4 & $5.3 \%$ \\
\hline Cervical & 1 & $1.2 \%$ \\
\hline LSCS scar & 2 & $2.6 \%$ \\
\hline Tubal abortion & 13 & $17.1 \%$ \\
\hline
\end{tabular}

The commonest site of ectopic pregnancy was fallopian tube in which ampullary accounted for $42.1 \%$ of total followed by isthmic in $25 \%$ of patients Table 3 .

On per operative findings rupture was present in $72.4 \%$ cases, $17.1 \%$ tubal abortion with $10.5 \%$ as unruptured cases (Table 4).
Table 4: Per operative findings and fate of ectopic pregnancy.

\begin{tabular}{|lll|}
\hline Per operative findings & No. of patients & $\%$ \\
\hline Rupture & 53 & $69.73 \%$ \\
\hline Tubal abortion & 13 & $17.1 \%$ \\
\hline Unruptured & 10 & $13.15 \%$ \\
\hline
\end{tabular}

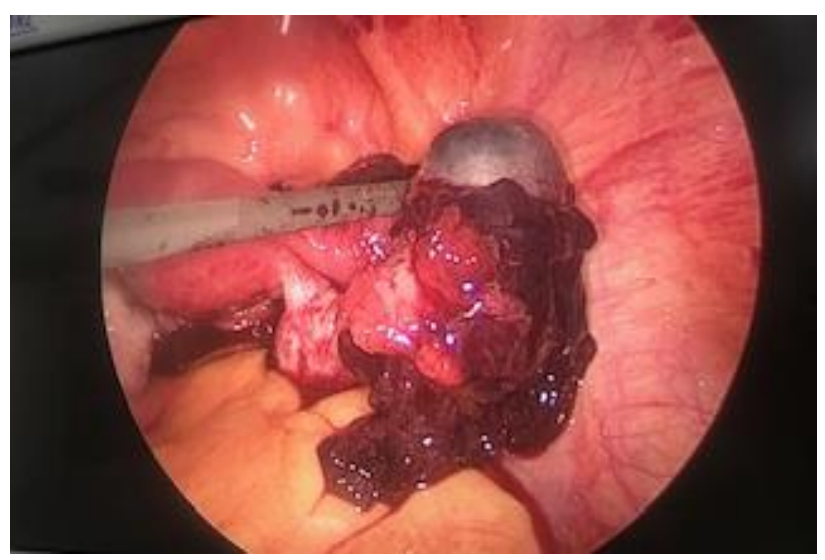

Figure 2: Laparoscopic view of unruptured ectopic in fallopian tube.

Table 5: Types of treatment modalities offered to patients.

\begin{tabular}{|lll|}
\hline Treatment modality & No. of patients & $\%$ \\
\hline Laparotomy & 62 & $81.6 \%$ \\
\hline Laparoscopy & 7 & $9.2 \%$ \\
\hline Laparoscopy f/b laparotomy & 2 & $2.6 \%$ \\
\hline Medical & 1 & $1.3 \%$ \\
\hline Conservative & 2 & $3.9 \%$ \\
\hline Suction and evacuation & 2 & $2.6 \%$ \\
\hline Uterine artery embolization & 1 & $1.3 \%$ \\
\hline
\end{tabular}

Table 6: Type of surgeries.

\begin{tabular}{|lll|}
\hline Types surgeries done & No. of patients & $\%$ \\
\hline $\begin{array}{l}\text { Laparoscopic } \\
\text { salpingectomy }\end{array}$ & 7 & $9.2 \%$ \\
\hline Salpingectomy & 54 & $71.05 \%$ \\
\hline Salpingoopherectomy & 5 & $6.6 \%$ \\
\hline Salpingostomy & 0 & $0 \%$ \\
\hline Ruptured cornu resection & 4 & $5.3 \%$ \\
\hline Pyoperitoneum drainage & 1 & $1.3 \%$ \\
\hline
\end{tabular}

A total 71 patients were managed surgically out of which 62 had laparotomy and 9 had laparoscopy (Figure 2). Two patients had laparoscopy followed by laparotomy. One patient was given medical management; two patients were followed with expectant management. For one patient with cervical pregnancy uterine artery embolization was done followed by USG guided suction and evacuation. One patient of scar site ectopic pregnancy was managed with USG guided suction and evacuation whereas in other patient of scar site ectopic 
pregnancy $\beta$ HCG was in falling trends so expectant management was continued (Table 5).

Salpingectomy was done in 61 cases and salpingoopherectomy was done in 5 cases where generalized oozing was present, and haemostasis was difficult to achieve. Rudimentary ruptured horn resection was done in 4 patients of accessory horn rupture. One patient had pyoperitoneum and tubo-ovarian abscess on per operative findings which was drained, and endometrial curettage was done (Table 6).

Table 7: Mortality and associated morbidity.

\begin{tabular}{|lll|}
\hline Morbidity and mortality & No. of patients & $\%$ \\
\hline Mortality & 0 & $0 \%$ \\
\hline ICU admissions & 11 & $14.5 \%$ \\
\hline Blood transfusions & 60 & $78.9 \%$ \\
\hline Hysterectomy & 0 & $0 \%$ \\
\hline Salpigo-opherectomy & 5 & $6.6 \%$ \\
\hline Prolong hospital stay & 0 & $0 \%$ \\
\hline Wound Sepsis & 1 & $1.3 \%$ \\
\hline
\end{tabular}

The mean duration of hospital stay was 5.6 \pm 2 days. 60 (78.9\%) patients required blood transfusion, 11 (14.5\%) patients were admitted to ICU and one required ventilator support as she developed pulmonary edema due to volume overload. There was $0 \%$ mortality in this study and one patient had wound sepsis in post-operative period (Table 7).

Table 8: Associated risk factors for ectopic pregnancy.

\begin{tabular}{|lll|}
\hline Risk factor & No. of patients & $\%$ \\
\hline Ligation and tubectomy & 3 & $3.9 \%$ \\
\hline H/o infertility & 6 & $7.8 \%$ \\
\hline H/o previous ectopic & 2 & $2.6 \%$ \\
\hline PID & 4 & $5.2 \%$ \\
\hline IUCD & 3 & $3.9 \%$ \\
\hline $\begin{array}{l}\text { H/o previous surgeries } \\
\text { (including LSCS) }\end{array}$ & 3 & $3.9 \%$ \\
\hline ART & 2 & $2.6 \%$ \\
\hline H/o previous abortions & 28 & $36.8 \%$ \\
\hline No risk factor & 34 & $44.7 \%$ \\
\hline
\end{tabular}

In evaluation of risk factor $36.8 \%$ had history of previous abortions, $7.8 \%$ had history of infertility, $3.9 \%$ had history of previous surgeries including LSCS, laparotomies and ligations, 3.9\% were IUCD users, 5.3\% had history of pelvic infections and $2.6 \%$ had undergone ART. Still a large majority of patients $44.7 \%$ had no known risk factors Table 8.

\section{DISCUSSION}

In the present study ectopic pregnancy had its peak incidence in 21-30 years age group and is more common in multigravida. Similar Incidence has been reported in studies by Rashmi et al, Swami et al, Tahmina $\mathrm{S}$ et al, and Chate TM et al. ${ }^{4,5,8,9}$ This could be because these are the peak reproductive years in which females are more exposed to STDs, abortion and puerperal sepsis.

Pain was commonest symptom in our study followed by bleeding per vaginum (BPV) seen in $96.1 \%$ and $88.2 \%$ respectively. In study by Rashmi et al, pain was the commonest symptom $89.2 \%$ followed by amenorrhea $77.5 \%$ and BPV in $42.3 \%{ }^{4}$ Swami et al, in their study also reported pain as commonest symptom present in nearly $100 \%$ of patients followed by amenorrhea and BPV in $97.05 \%$ and $76.47 \%$ respectively. ${ }^{9}$ Tahmina $\mathrm{S}$ in their study reported classic triad in 40.35 of patients with pain as the commonest symptom present in $81.9 \%$ of patients. $^{5}$

A total $85.1 \%$ patients in our study presented as acute cases whereas in study by Swami et al, $85.29 \%$ were chronic cases. ${ }^{9}$

The most common clinical sign and ultrasound finding in our study was adnexal mass which was present in $98.7 \%$ patients. The other commonest USG finding was presence of free fluid in nearly $84.2 \%$. Swami et al in their study reported adnexal mass on USG in $64.70 \%$ of patients. Empty uterine cavity was present in $100 \%$ of patients in present study and in study by Swami et al. ${ }^{9}$ Rashmi et al, also reported heterogeneous adnexal mass in $40.5 \%$ patients and free fluid in POD in $83.8 \%$ patients. ${ }^{4}$ The commonest site of ectopic pregnancy in our study was tubal in which ampullary accounted for $42.1 \%$ followed by isthmic in $25 \%$. Similar incidences were reported by Rashmi et al, and Vyas PS et al, were ampullary was commonest followed by isthmic., ${ }^{4,5}$

Surgery was the main treatment modality in $93.4 \%$ patients of study, $84.2 \%$ had laparotomy, whereas $9.2 \%$ had laparoscopy, $2.6 \%$ had laparoscopy followed by laparotomy due to presence of massive haemoperitoneum and $2.6 \%$ had USG guided D/C in OT. Salpingectomy was the preferred surgery in $80.25 \%$ cases and salpingoopherectomy was done in $6.6 \%$ cases. In study by swami et al $88.24 \%$ patient had surgical management, in study by Rashmi et al, surgery was main treatment modality with salpingectomy as the commonest surgery and in study by Tahmina $S$ et al $80.5 \%$ patients were managed with surgery, $13.9 \%$ were managed medically and $5.6 \%$ had failed medical requiring further surgery. ${ }^{4,5}$

In one patient of cervical ectopic pregnancy (CEP) with very high values of $\beta$ HCG 25678 bilateral uterine artery embolization was done to reduce the chance of bleeding as CEP has high risk of hemorrhage. Ultrasound guided suction and evacuation was done in major OT after embolization.

As the incidence LSCS deliveries are increasing the incidence of scar site ectopic pregnancies are also increasing. In this study author had two cases of LSCS 
scar pregnancy. Ultrasound is the primary mode for diagnosing scar site ectopic and MRI can be used as second line investigation. Empty uterine cavity and empty endocervical canal, implantation of Gsac at the level of previous cesarean scar with absence or thinning of myometrium between Gsac and bladder are important features seen on USG and MRI (Figure 3 and 4). Both the patients of ectopic scar site in study group had $\beta$ HCG less than 1000, as such expectant management was planned in both of them. First patient's $\beta$ HCG was in decreasing trend and reverted back to normal (less than 10 ) in 10 weeks while in second patient the $\beta$ HCG value plateaued at 278. So, ultrasound guided suction and evacuation was done in major OT. Implantation of gestation sac in fibrotic scar tissue leads to scar site pregnancy. The vascularity of this fibrotic scar is poor and sometimes may lead to spontaneous failure of these pregnancy. Also, the chance of success of systemic injection of methotrexate is also poor in these patients due to poor vascularity. Sometimes these pregnancies may result in torrential hemorrhage due to dehiscence or rupture of scar site and laparotomy is required in such patients. $^{10,11}$

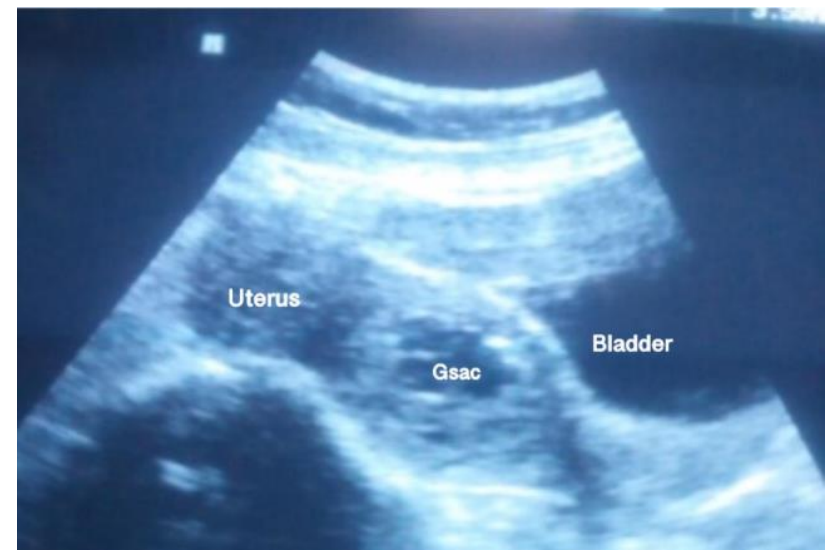

Figure 3: Ultrasound of Ectopic Gestation sac near LSCS scars with empty endometrial cavity.

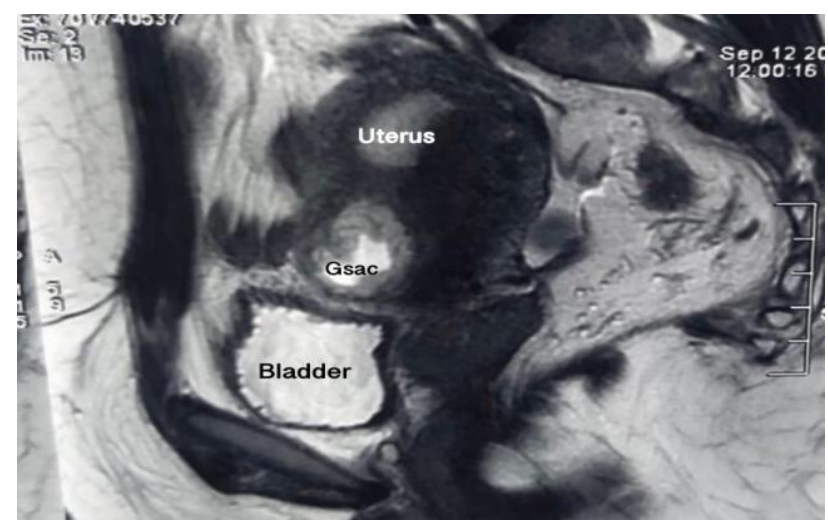

Figure 4: MRI of caesarean scar site ectopic showing empty uterus and endocervical canal with loss of myometrium in between Gsac and bladder.
Most of the patients $44.7 \%$ had no associated risk factors. Previous history of abortion was present in $36.8 \%$, history of infertility was present in $7.8 \%$, history of pelvic infections was present in $5.2 \%$, history of previous surgeries was present in $3.9 \%$ and history ligation was present in $3.9 \%$, other less common risk factors were IUCD use and ART.

Rashmi et al, in their study reported that $37.83 \%$ had no associated risk factors and some of the common risk factors in their study were $\mathrm{h} / \mathrm{o}$ previous tubectomies, $\mathrm{h} / \mathrm{o}$ infertility, h/o previous ectopics, h/o of PID and h/o previous surgeries such as, appendicectomy and LSCS. ${ }^{4}$ Tahmina S, reported previous abortions and previous pelvic surgery as the commonest risk factor present in $36.1 \%$ and $37.5 \%$ of their patients. ${ }^{5}$ Vyas PS in their study found that previous or present history of PID was the commonest risk factor $(25 \%)$ followed by previous history of abortions (21.43\%) and $37.76 \%$ had no associated risk factors. ${ }^{12}$

There was no mortality, 11 (14.5\%) patients required ICU admission and one required ventilator support for pulmonary edema due overzealous fluid supplementation. $78.9 \%$ patients required blood transfusions, $6.6 \%$ had salpingoopherectomy and $1(1.3 \%)$ patient had wound sepsis in post-operative period. Tahmina $\mathrm{S}$ also reported $0 \%$ mortality while $86.1 \%$ of their patients needed blood transfusions, ICU admissions in $8.3 \%$, wound infections in 5.6\% and Transfusion related acute lung injury in $2.8 \%$ patients. ${ }^{5}$ Rashmi et al, in their study reported $0 \%$ mortality, $97.29 \%$ need of blood transfusions and one (2.7\%) patient developed transfusion related acute lung injury. ${ }^{4}$

\section{CONCLUSION}

Ectopic pregnancy is one of the leading causes of maternal morbidity and mortality in the first trimester of pregnancy. In the present study though there was no mortality, a large number of patients were referred from peripheral hospital in compromised state so most of them required blood transfusion and open surgeries. Surgery both laparatomy and laparoscopy still remains the main treatment modality depending upon patient's condition. With the evolution of science and technology the diagnosis and treatment of ectopic pregnancy has had revolutionary changes and with early detection conservative options can be considered in haemodynamically stable patients. Ultrasonography by and large is the main imaging modality and wherever available MRI can be a useful adjunct. Previous histories of abortion, pelvic infections, ectopic pregnancies, abdominal and tubal surgery were some of the identifiable risk factors for ectopic pregnancy.

Funding: No funding sources

Conflict of interest: None declared

Ethical approval: The study was approved by the Institutional Ethics Committee 


\section{REFERENCES}

1. Te Linde. Operative Gynecology. $11^{\text {th }}$ Edition. Howard W Jones and John A Rocks. Chapter 34; 2015:771-798.

2. O'Herlihy C. Centre for maternal and child enquiries. Deaths in early pregnancy. Saving mothers' lives: reviewing maternal deaths to make motherhood safer: 2006-2008. The eight Report of Confidential Enquiries into maternal Deaths in the United Kingdom. BJOG. 2011;118 Suppl 1:81-4.

3. Centers for disease control and prevention (CDC). Ectopic pregnancy: United States, 1990-1992. MMWR Morbidity Mortality Weekly Rep. 1995;44:46-8.

4. Gaddagi RA, Chandrashekhar AP. A clinical study of ectopic pregnancy. J Clin Diagn Res. 2012;6:867-9.

5. Tahmina S, Daniel M, Solomon P. Clinical analysis of ectopic pregnancies in a tertiary care centre in Southern India: a six-year retrospective study. J Clin Diagn Res. 2016;10(10):QC13-16.

6. Ectopic pregnancy and miscarriage. National Institute of Clinical Excellence. Manchester: NICE; 2019. Available at: https://www.nice.org.uk/ guidance/ng126/resources/ectopic-pregnancy-andmiscarriage-diagnosis-and-initial-management-pdf66141662244037. Accessed on 17 ${ }^{\text {th }}$ April 2019.
7. Daftary SN, Desai SV. Selected topic in Obstetrics and Gynaecology-part 1, chapter 8. Current concepts in management of ectopic pregnancies; 2007:92-93.

8. Chate MT, Chate B. Clinical study of ectopic pregnancy. Int J Repro Contracept Obstet Gynecol. 2017;6:3498-501.

9. Swami MB, Sharma Parul, Tyagi M. Clinical study of ectopic pregnancy. J Evolut Med Dent Sci. 2015;4(86):15057-62.

10. Patel MA. Scar ectopic pregnancy. J Obstet Gynaecol India. 2015;65(6):372-5.

11. Takeda K, Maackay J, Watts S. Successful management of cervical ectopic pregnancy with bilateral uterine a. embolization and Methotrexate. Case Repo Emer Med. 2018:Article ID 9593824.

12. Vyas PS, Vaidya P. Epidemiology, diagnosis and management of ectopic pregnancy, 2000. Available at: http://www.bhj.org/journal/2000_4203_jul00/ origi nal_458. Accessed on July 2000.

Cite this article as: Ara A, Chawla I, Agarwal R, Manjhi B. Clinical study on presentation and management of ectopic pregnancies in a tertiary care centre. Int J Reprod Contracept Obstet Gynecol 2020;9:173-8. 